\title{
CONSIDERAÇÕES SOBRE A HISTORIOGRAFIA DO "AVERROÍSMO"
}

\author{
Idalgo José Sangalli"
}

SINTESE - O autor tece algumas considerações em torno do contexto e das características do principal alvo das condenaçōes de 1277: o movimento filosófico cunhado de "averroísmo". Aponta a necessidade de rever a equivocada leitura tradicional realizada, principalmente por historiadores como Renan e Mandonnet, sobre a posição e a atitude filosófica de seus principais expoentes (Síger de Brabante e Boécio de Dácia). Estes "aristotélicos radicais" seguem a concepção de filosofia de Aristóteles, contaminada por elementos neoplatônicos e pela interpretação árabe, os quais são justamente caracterizados nos estudos recentes de modo mais moderado, reavaliando-se as suas contribuiçōes nos debates em torno do estatuto teórico do fazer filosófico.

PALAVRAS-CHAVE - Filosofia. Aristotelismo greco-árabe. Averroísmo. Siger de Brabante.
ABSTRACT - The author presents some reflections concerning the context as well as the caracteristics of that which was the main target of the 1277's condemnation: the philosophical current known as "averroism". The author also points up the need to reconsider the usual and misinterpreted reading about the place and the philosophical attitude of its main exponents (Siger de Brabant and Boecio de Dacie), made specifically by historiographers as such as Renan and Mandonnet. Those "radicals aristotelians" followed the aristotelic philosophy, being also impregnated by neoplatonic elements and by the arabian interpretations, which are taken in recent studies in a restrained view, being revalued their contribution to the debat concerning the theoretical status of the philosophical acting.

KEY WORDS - Phylosophy. Greek-arabian aristotelism. Averroism. Siger de Brabant.

Era comum até algumas décadas - e para alguns ainda é - considerar Síger de Brabante (c.1240-1280/84), Boécio de Dácia (?-?) - foi colega de Síger -, entre outros mestres "artistas" mais ou menos conhecidos, como sendo "averroístas", isto é, seguidores das idéias de Averróis. Eles pretenderam fazer filosofia pura, opondo-se radicalmente às teorizações teológicas vivenciadas, principalmente, no ambiente universitário da Faculdade de Teologia de Paris, no auge da escolástica,

Este texto é parte da tese de doutorado em Filosofia Medieval "O Filósofo e a Felicidade: o filosofar como condição para a felicidade em Síger de Brabante, Boécio de Dácia e Giácomo de Pistóia", defendida em março de 2004, na PUCRS.

Professor do Departamento de Filosofia da Universidade de Caxias do Sul (UCS). 
como ficou tradicionalmente conhecido este período do século XIII. ${ }^{1}$ A história do averroísmo, com suas complexas nuances históricas ou construções lendárias, está diretamente relacionada à recepção das obras de Averróis entre os latinos, ou melhor, ao tipo de interpretação dada, pelo Comentador, ao pensamento de Aristóteles.

Esta história, que ficou conhecida com a controversa categoria historiográfica de "averroísmo latino", ocorreu, primeiramente em Paris, no século XIII, a partir das traduções do árabe, seguidas das condenações de 1270 e de 1277 e, numa segunda fase, na Itália, no século XV e início do XVI, com as novas traduções do hebraico, juntamente com as idéias sustentadas por pensadores como Dante Alighieri (1265-1321), Marsílio de Pádua (1275/1280-1342/1343), Ângelo d'Arezzo (c.1318), Tadeu d'Alderotto (?-1295), Tadeu de Parma (c.1318), Paulo Nicoletti (Paulus Venetus) (1369-1429), Nicoletto Vernia (?-1499), Agostinho Nifo (c.14731538), Alexandre Achillini (1463-1512) entre outros. ${ }^{2}$

Em primeiro lugar, deve-se alertar que depois das conclusões apresentadas, ainda na década de 60, por Steenberghen ${ }^{3}$ e reconfirmadas por diversos autores, ${ }^{4}$ não houve um "averroísmo latino", como foi apresentado por Renan ${ }^{5}$ num grande trabalho pioneiro, porém equivocado e, seguido, por Mandonnet ${ }^{6} \mathrm{e}$, até mesmo, por Gilson, "entre outros. A posição filosófica sustentada, de modo bastante particular, por Síger de Brabante e o seu colega Boécio de Dácia, ambos mestres da

O esquema tradicional de ver o século XIII como "a idade de ouro da escolástica", o ápice de uma experiência que acaba e causa uma grave crise, um periodo de decadência no século XIV, deveria já estar completamente superado. Conceitos usuais como "medievo", "escolástica" são, recentemente, interpretados de modo diferente dos esquemas tradicionais. Sobre isto, vide: LIBERA, A. De. La philosophie médiévale. Paris: Presses Universitaires de France, 1993; BIANCHI, L. La filosofia nelle università (secoli XIII-XIV). Firenze: La Nuova Italia, 1997; QUINTO, R. "Scolastica". Storia di un concetto. Padova: Il Poligrafo, 2001

2 Sobre isto vide, HAYOUN, M-R; LIBERA, A de. Averroès et l'averroisme. Paris: Presses Universitaires de France, 1991, especialmente nos capitulos VII, VIII e IX, p. 75-122. No caso do termo "averroista" teria surgido primeiramente em alguns autores (Tomás de Aquino, Raimundo Lullio), em torno de 1270. Uma boa revisāo crítica da historiografia sobre 0 averroísmo foi apresentada por FIORVANTI, G. "Boezio di Dacia e la storiografia sull'Averroismo". In Studi Medievali, VII, Spoleto: Centro Italiano di Studi sull'Alto Medioevo, 1966, p. 283-322.

3 STEENBERGHEN, F. V. La philosophie au XIIIe siècle. 2. ed. Louvain-La-Neuve: L'ISP, Louvain: Peeters, 1991, p. 321-359. Idem. Maitre Siger de Brabant. Louvain: Publications Universitaires; Paris: Vander-Oyez, 1977, p. 393-395 e 397-399.

4 Podemos destacar: DUIN, J. J. La doctrine de la providence dans les écrits de Siger de Brabant. Louvain: Institut Supérieur de Philosophie, 1954, p.400-442; BAZAN, B. "La réconciliation de la foi et de la raison était-elle possible pour les aristotéliciens radicaux?" In Dialogue, 1980, p. 237-251; HISSETTE, R. Enquête sur les 219 articles condamnés à Panis le 7 mars 1277. Louvain/Paris: Publications Universitaires/Vauder-Oyez, 1977, p. 22-23; BIANCHI, L. L'errore di Aristotele. La polemica contro l'eternità del mondo nel XIII secolo. Firenze: La Nuova Italia, 1984, p.175-177; PUTALLAZ , F-X e IMBACH, R. Professione filosofo Sigien di Brabante. Milano: Jaca Book, 1998, p. 11-18.

5 RENAN, E. Averroès et l'averroisme: essai historique. (Paris, 1852, 3. ed. 1866), Hildesheim, etc. G. Olms Verlag, 1986.

6. MANDONNET, P. Siger de Brabant et l'averroisme latin au XIIle siècle, (Réimpression de l'édition de Fribourg, 1899), Genève: Slatkine Reprints, 1976.

- GILSON, E. "Compte rendu de F. Van Steenberghen, Siger de Brabant d'après ses œuvres inédites, t. II". In Bulletin thomiste XVII-XIX, 6 (1940-1942), p. 5-22. 
Faculdade de Artes, seja em relação às teses de Averróis (unidade do intelecto material ou potencial, a relação entre a filosofia e a religião, entre outras), seja no confronto das teses julgadas pela ortodoxia da época como heréticas (eternidade do mundo, necessitarismo metafísico e criação por intermediários, determinismo astrológico, negação da providência divina, unidade do intelecto para toda a humanidade), é hoje justamente qualificada de modo mais "moderado". Assim, o pensamento destes autores é enquadrado como "aristotelismo independente" ou "filosofia independente" ou, mais usualmente, "aristotelismo heterodoxo" ou "aristotelismo radical" ou "aristotelismo integral". ".

Ainda, numa interpretação mais restritiva em termos de dependência direta e fiel, como afirma Ghisalberti, "l'unica tesi di Averroè accettata tale e quale nel mondo latino del sec. XIII fu quella dell'unicità dell'intelletto possibile, fatta propria da Sigieri di Brabante; [... in tutte le altre tesi Sigieri non segue Averroè..." ${ }^{10}$ Esta posição é condividida também por Steenberghen ${ }^{11}$ e, de modo mais aprofundado, por Bianchi que, corroborando a tese de Gauthier, diz que foram Alberto Magno (1206ca.-1280), Roberto Kildwardy (?-1279), Boaventura (1217-1274) e Tomás de Aquino (1225-1274) a ler nas páginas do comentário de Averróis ao De Anima a doutrina da unidade do intelecto, assumida depois por Síger na sua obra juvenil Quaestiones in tertium de anima. Antes de 1250, tal doutrina do Comentador não era conhecida pelos artistas -, afirma: "il 'monopsichismo averroísta', anzi lo stesso 'averroismo' si rivela cosi 'un'intervenzione dei teologi'"'. ${ }^{12}$

A posição sustentada por esses mestres de Artes em relação à discutida questão fé-razão não foi de conciliá-las, como fez Tomás de Aquino; não foi, porém, de pura e simples oposição como saltava aos olhos (ou queriam que saltasse aos olhos) de muitos teólogos ortodoxos receosos do avanço, da autonomia e da reivindicação de algo mais para a filosofia que ser apenas "ancilla teologiae". Nisto se insere o problema da chamada "evolução" do pensamento do principal expoen-

Cf. STEENBERGHEN, F. V., La philosophie au XIIIe siècle. 1991, p. 354-359; idem. Maittre Siger de Brabant. 1977, p. 258.

- Cf. LIBERA, A de, Albert le Grand et la philosophie. Paris: Vrin, 1990, p. 269.

10 GHISALBERTI, A. "Boezio di Dacia e l'averroismo latino" In Actas del V Congreso Intemacional de Filosofia Medieval. V. II, Madrid: Nacional, 1979. p. 772.

"Cf. STEENBERGHEN, F. V., La philosophie au XIlle siècle. 1991, p. 352 s.

12 BIANCHI, L., L'errore di Aristotele... 1984, p. 28s. Cf. GAUTHIER, R. A., "Notes sur les débuts (1225-1240) du premier 'averroïsme'". In: Revue des Sciences Philosophiques et Théologiques, LXVI, n. 3, Pans: Vrin, 1982, p. $321-73$ e "Notes sur Siger de Brabant. I. Siger de Brabant en 1265". In: ibid. LXVII, n. 2, Paris: Vrin, 1983, p. 201-32. Cabe observar que os ardorosos combates desencadeados desde 1300 pelo leigo Raimundo Lúlio contra os ideais dos clérigos averroistas muito contribuiu para a consolidação do rótulo "averroísta" como seguidores de Averróis. Embora Lúlio visasse mais o racionalismo árabe em seu conjunto do que Averróis, seus escritos, somados às 219 teses condenadas, deu apoio à interpretação histoniográfica de Renan. Vide: LIBERA, A. de. Pensar na Idade Média. Trad. Paulo Neves, São Paulo: Ed. 34, 1999, "O averroismo impossivel ou o teatro do ambiguo", p. 123-131. 
te dos mestres "artistas", Síger de Brabante, a partir da consideração da paternidade e cronologia de suas obras e dos elementos internos aos textos, tratados pela historiografia filosófica produzida de De Wulf à Steenberghen. ${ }^{13}$

O movimento filosófico promovido na Faculdade de Artes de Paris, que retomou a filosofia pagã grega, o aristotelismo - com as suas poderosas teorias "científicas", especialmente na física e na cosmologia, que forneciam um complexo "sistema explicativo da natureza", explicando os fenômenos reais através de racionais nexos de causalidade, bem como um conjunto de conceitos lógicos, metafísicos, éticos, racionalmente ordenados, coerentes, que dava unidade e confiabilidade enquanto sistema filosófico - baseava-se na exclusividade e confiança no uso da razão natural e da "recusa" das respostas dadas pela fé. Certamente, isto devia causar preocupação e medo em todos aqueles espíritos imbuídos exclusivamente da mensagem evangélica e de uma concepção de filosofia agostiniana. Ademais os "aristotelismos" da escolástica se distinguem entre si, pois são elaborações de indivíduos que, além de reflexões determinadas por horizontes e interesses culturais diferentes, desempenham papéis profissionais diferentes (teólogos, médicos, juristas, filósofos).

Para a Faculdade de Teologia, perder o domínio sobre a filosofia, concordar que esta deixasse de ser simples propedêutica da teologia era uma concessão muito perigosa que poderia ter resultados teórico-práticos contrários aos ideais da fé. A crise da escolástica se formou de uma filosofia independente, com o surgimento de um intelectual profissional, primeiramente, no seio da universidade e, em seguida, fora dela - filosofia "extramuros" - com objetivos e idéias diferentes das dos teólogos, especialmente, Tempier. ${ }^{14}$ Estes, por sua vez, procuraram combater e travar, numa multiplicidade de contextos teóricos e disciplinares, o surgimento desta nova figura e seus ideais, que culminaram no âmbito moral, com as condenações.

No fundo, o medo do perigo de uma revolução cultural que colocasse em risco a existência e a própria unidade da cristandade - que começou na passagem do século XIII ao XIV e que alguns séculos mais tarde acabou acontecendo - motivou uma tomada de posição por parte da comissão censória comandada por Tempier. As reações negativas e censórias daquelas teses contrárias à "Weltanschauung" cristã, perpetuadas doutrinalmente e historiograficamente, pelos "justificacionistas" alinhados a Tempier e, por outro lado, pelos "críticos" de tais medidas têm, até hoje, servido de paradigma nos debates interpretativos sobre a "crise da escolástica", as relações entre razão e fé e o "nascimento dos intelectuais".

13 Cf. DE WULF, M., Histoire de la Philosophie Médiévale. Louvain/Paris: Institut Supérieur de Philosophie/Vrin, 1936. Em diversas obras, aqui citadas, Steenberghen defende a idéia de uma evolução do pensamento de Siger. No caso de críticas às teses "evolucionistas", vide: DUIN, J. J., op. cit. p. 396-397 e 407: ARGERAMI, O., "La cuestion 'De aeternitate mundi': posiciones doctrinales". In: Sapientia, XXVII, 1972-73, p. 189 e 205-7; BAZAN, B. C., op. cit. 1980, p. 238 e BIANCHI, L., L'errore di Anistotele... 1984, p. 89-91. 
Para além das motivações e do sentido da intervenção episcopal - que por si só demandaria uma profunda análise crítica - parece que os filósofos "averroístas" tiveram como marca principal reivindicar o direito legitimo de um tipo de "racionalidade" baseada nas próprias forças limitadas da razão natural humana, ou seja, da autonomia e independência do investigar filosófico-científico, da consciência da competência específica de sua profissão de "artista", especialmente no uso dos textos de Averróis como "instrument de travail"15 para compreender "corretamente" aquele que era considerado o Filósofo. Atrás deste movimento "averroísta", como parte central deste "período de aculturação" - que, na verdade, está intimamente ligado e confundindo-se reciprocamente - estão o nascimento das universidades e a entrada maciça do aristotelismo greco-árabe.

Um dos resultados dos confrontos doutrinais, entre os "artistas" e os teólogos, a partir da introdução de Aristóteles, será particularmente dramático para esta "corrente de esquerda" com suas primeiras manifestações tidas como "heterodoxas", em torno de 1265. Foi denunciada, pela primeira vez, por representar um perigo à ortodoxia, pelo então ministro geral dos frades menores, Boaventura, em torno de 1267 e terminou com as condenações das 219 (ou 220) proposições pelo bispo Tempier, em $1277 .{ }^{16}$ Depois da primeira condenação de 10 de dezembro de 1270, ocorreram fortes conflitos internos entre as quatro "nações" (francesa, normanda, picarda e inglesa), tanto no sentido doutrinal, quanto no sentido políticoorganizacional, culminando com uma divisão no interno da própria Faculdade de Artes, que durou mais de três anos. ${ }^{17}$

Nem todas as proposições condenadas, à luz de uma análise mais aprofundada, eram heterodoxas e Síger não era o único alvo das condenações de Tempier,

15 STEENBERGHEN, F. V., La philosophie au XIIle siècle. 1991, p. 352.

so Para uma análise detalhada das teses condenadas, no que diz respeito ao seu caráter heterodoxo (averroísta), a intenção dos censores e a quem propriamente eram endereçadas, convém consultar R. HISSETTE, op. cit. Também, o importante trabalho de BLANCHI, Luca, II vescovo e i filosofi: la condanna parigina del 1277 e l'evoluzione dell'aristotelismo scolastico. Bergamo: Pierluigi Lubrina, 1990; e de LAFLEUR, C., La condamnation parisienne de 1277. Paris: Vrin, 1999. Sobre a intervenção de Boaventura, vide: STEENBERGHEN, F. V. Maître Siger de Brabant. 1977, p. 33-46; nāo esquecendo o trabalho de MANDONNET, P., op. cit., especialmente o cap. IX, sobre 'condamnation du péripatétisme 1277', p.ccxxix-cclxii. Por sua vez, Libera sustenta uma hipótese, a nosso aviso pouco plausivel, que o verdadeiro perigo que Tempier quis conjurar não estava em Boécio de Dácia e nem em Averróis, mas nos escritos de Maimônides, onde os latinos aprenderam, da experiência histórica vivenciada pelo mundo islâmico, a distinguir filosofia, fé e teologia. (LIBERA, A. de, Pensar na Idade Média. 1999, p.119s.). Vide, também, PICHÉ, David, La condammation pansienne de 1277. Nouvelle édition du texte latin, traduction, introduction et commentaire. Paris: Sic et Non, 1999. Nesta nova ediçâo das teses condenadas por Tempier, Piché demonstra a necessidade de corrigir alguns pontos propostos no Chartularium Universitatis Panisiensis e apresenta a descoberta de uma nova tese condenada, conforme testemunho de quatro manuscritos. Com isto, seriam 220 as teses condenadas em 1277. Contudo, a interpretação dada por Piché, em alguns pontos da obra, repete opiniōes já consagradas e, por outro lado, sustenta uma leitura do De Summo Bono, de Boécio de Dácia, no contexto das teses condenadas, que é muito discutivel. Sobre isto, vide a crítica de BIANCHI, L., "Felicità terrena e beatitudine ultraterrena. Boezio di Dacia e l'articolo 157 censurato da Tempier". In: Chemins de la Pensée Médiévale. 20, 2002, p. 193-214.

17 Vide: MANDONNET, P. op. cit. p. ccvii-ccxxvii; STEENBERGHEN, F. V., Maittre Siger de Brabant. 1977, p. 80-88. 
pois o próprio Boécio de Dácia e sua obra De Summo Bono também foram inquestionavelmente alvos principais da comissão censória. Infelizmente, o conhecimento, ainda hoje, sobre este ambiente e as suas variáveis é bastante limitado, menos pela falta de documentação, do que pelo tipo de orientação dominante que guiou a maior parte da historiografia na convicção de que a "verdadeira" filosofia medieval não podia ser a dos diversos comentários obscuros ou suspeitos de Aristóteles, mas a das grandes "sinteses" dos mais célebres teólogos. ${ }^{18}$

No entanto, com cada vez mais consciência da natureza, dos métodos e da autonomia científica do saber aristotélico e na medida em que os estudos dos diversos escritos aristotélicos eram incorporados no programa de ensino da Faculdade de Artes $^{19}$, tomava-se cada vez mais saliente a corrente de pensamento (aristotelismo radical) orientada em separar, metodologicamente, aquilo que era específico da filosofia, enquanto metafísica, diante da teologia, enquanto ciência sacra ou sagrada escritura. Ou seja, de modo mais restrito, separam-se as discussões ético-morais de natureza exclusivamente filosófica das questões de teologia moral reivindicadas pelos teólogos cristãos. O próprio Alberto Magno contribuiu para esta tomada de consciência, quando distinguiu claramente a filosofia da teologia, o método racional do recurso à autoridade divina, as leis naturais das intervenções milagrosas de Deus. ${ }^{20}$

Portanto, tais discussões e conflitos, em torno da natureza e status da filosofia, marcaram fortemente 0 ambiente universitário da segunda metade do século XIII, determinando um conjunto de posições intelectuais divergentes, devedoras porém de uma base filosófica comum, que pode ser caracterizada como aristotelismo-platonizante, como já foi dito. No caso dos filósofos em discussão, parece mais adequado falar em "aristotelismo radical" e, no que compete à posição pessoal de Síger, também parece adequado “... di parlare di 'filosofia sigeriana' - o quantomeno di 'aristotelismo sigeriano'. ${ }^{21}$

18 BIANCHI, L.; RANDI, E., Le verità dissonanti. Roma/Bari: Laterza, 1990, p. 20. Neste ponto os autores criticam a posição de Gilson e seguidores por terem "passivamente accolto l'idea che l'unico aristotelismo scolastico teoricamente interessante e storicamente influente fosse quello riveduto e corretto da Guglielmo d'Auvergne o da Alberto Magno, da Tomasso d'Aquino o da Enrico di Gand, mentre quello dei magistri Artium, pregiudizialmente liquidato come 'dogmatico' e 'sterile', avrebbe avuto al più il compito negativo di esasperare i contrasti, di mostrare l'impercorribilità della strada nella quale ci si era incamminati con esagerata fiducia, inducendo ad abbandonarla." (p. 20s.).

19 O aristotelismo entra de modo definitivo e oficialmente em 1255 com o novo estatuto da Faculdade de Artes. O "Guia dos Estudantes", também conhecido como Ripoll 109, exemplifica a forte presença da filosofia aristotélica no ensino dos mestres de artes. De escolas de artes liberais, passaram a ser escolas de filosofia anistotélicas. Sobre a produção intelectual destes mestres, vide os dois volumes: WEIJERS, Olga, "Le travail intellectuel à la faculté des arts de Paris: textes et maitres (ca.1200-1500)". In: Studia Artistarum. Paris: Brepols, 1997. Cf. STEENBERGHEN, F. V., Maître Siger de Brabant. 1977, p. 230. Nestas mesmas páginas encontramos algumas passagens citadas das obras de Alberto Magno sobre essas divisões.

2. Cf. BLANCHI, L., "Velare philosophiam non est bonum'. A proposito della nuova edizione delle Quaestiones in Metaphysicam di Sigeri di Brabante". In: Rivista di Storia della Filosofia. 40, n. 2, Milano: Franco Angelis, 1985, p. 263. 
Ao ler os textos sigerianos conhecidos, não poucos intérpretes costumavam dizer que nos primeiros escritos que a posição de Síger foi mais radical e, depois especialmente com sua obra tardia Quaestiones super librum de causis, a qual foi objeto de fortes debates sobre a sua autenticidade, que levou comentadores críticos como Grabmann, Gilson, a reverem as suas interpretações da filosofia de Síger - teria ocorrido uma acentuada atenuação das teses heterodoxas e o abandono da tese do monopsiquísmo, aproximando-se muito da posição de Tomás de Aquino.

Essa questão da evolução, ou não, da posição sigeriana, independentemente de quais textos estejam em juízo, é central para uma correta interpretação de seu pensamento, pois trata-se da posição filosófica, dos ideais filosóficos, relacionados com a própria concepção de felicidade defendida por ele e seus colegas. O que está na base dos movimentos intelectuais, nas várias personalidades filosóficoteológicas deste período, é o tipo de relação entre filosofia e teologia, isto é, como se deu a retomada e o desenvolvimento da metafísica como disciplina filosófica. No fundo, o que está em cena é o estatuto teórico da filosofia. Contudo, não se pode esquecer que são muitas as variáveis em jogo neste complexo cenário filosófico-teológico, que não pode ser entendido como posição unitária. Por exemplo, a influência do fator religioso, do ser acima de tudo cristão, sobre a produção intelectual não foi igual entre os pensadores medievais, assim como as concepçōes de filosofia, de metafísica, foram diferentes. Segundo Steenberghen,

elle [o fator religioso] est normalment plus forte chez un éveque (Augustin) ou un moine (Anselme) que chez un maitre de la faculté des arts (Siger de Brabant); elle s'exerce davantage sur le moraliste que sur le logicien ou le grammairien, sur le théologien (Albert, Bonaventure, Thomas) que sur le philosophe de profession (Nicolas de Paris, Siger de Brabant, Boèce de Dacie). ${ }^{22}$

Entender, porém, a concepção dos mestres de Artes, como fez Renan, ${ }^{23}$ como um movimento de oposição para resistir à opressão dominante do dogma cristão, com posições supostamente heréticas, sendo visto (tal movimento) como o aparecer de um breve momento da razão, ainda que subterraneamente, e que mostrava estar viva, apesar do longo período de esterilidade intelectual (e que atingirá o seu êxito só na modernidade), é um equívoco. Isto vale, também e principalmente, para Mandonnet ${ }^{24}$ que influenciou gerações e, apesar do importante trabalho de publicações dos textos de Síger, adotou o quadro interpretativo de Renan, perdendo, assim, a oportunidade de superá-lo. Exemplo disto nas afirmações:

[...] que l'ambition de Siger était de reproduire exclusivement la pensée d'Aristote. [...] En soi, la pensée de Siger est l'une des moins originales et des moins indépendantes du XIIIme siècle. Elle est asservie, et par principe, à Aristote et à Averroès. [...] Siger est donc à la fois extrêmement audacieux, et très peu indépendant. Son audace est dans l'affirmation de théories antichrétiennes qui sont le scandale de ses

22 STEENBERGHEN, F. V., Introduction à l'étude de la philosophie médiévale. Louvain/Paris: Publications Universitaires/Béatrice-Nauwelaerts, 1974, p. 86.

$\checkmark$ RENAN, E., op. cit. (1866), 1986.

24 MANDONNET, P., op. cit. (Fribourg, 1899). 
contemporains; son asservissement est dans le parti pris de ne s'écarter en rien de la pensée d'Aristote et d'Averroès, et de ne chercher pas à le faire progresser. ${ }^{25}$

À luz de interpretações mais recentes, como de Marlasca, ${ }^{26}$ de Gauthier ${ }^{27}$ ou, não tão recente, como de Steenberghen ${ }^{28}$ - este último apoiado pela contribuição de Dondaine e Bataillon, ${ }^{29}$ no tocante à paternidade sigeriana das Quaestiones super librum de causis, que forneceu dados decisivos para pôr fim às acirradas discussões entre o próprio Steenberghen ${ }^{30}$ e Nardi $^{31}$ ou mesmo Gilson ${ }^{32}$ - confirmase que Síger havia abandonado no final da sua carreira de mestre das Artes a doutrina da unidade do intelecto (monopsiquismo). ${ }^{33}$ Mas esta suposta evolução da posição sigeriana, em relação à unidade do intelecto, é questionada por autores que não seguem a orientação dada por De Wulf e criticam as conclusões de Steenberghen.

Quanto à interpretação de Grabmann, ${ }^{34}$ onde o averroísmo era por ele tido como um movimento de oposição à concepção cristã, contrário à fé e que só procedia "secundum viam philosophorum" sobrevivendo, apesar das condições adversas, até o alvorecer da modemidade, revelou-se deficitária. Ainda sobrevivem, porém, afirmações do tipo mandonetiano de Síger "averroísta" ou, na esteira de Tempier, como inventor e defensor da doutrina da "dupla verdade" (duplex veritas), ${ }^{35}$ não só em certos manuais de história da filosofia, os quais contribuem na perpetuação destes equívocos, mas também em trabalhos apresentados em con-

${ }^{25}$ Idem, ibid. p. 203.

26 SIGER DE BRABANT, Quaestiones super librum de causis. ed. critique A. Marlasca, Philosophes Médiévais, tome XII, Louvain/Paris: Publications Universitaires, 1972.

GAUTHIER, R.-A., "Notes sur Siger de Brabant, I. Siger en 1265". In: Revue des Sciences Philosophiques et Théologiques, 67 (1983), p. 201-232; Idem. "Notes sur Siger de Brabant, II. Siger en 1272-1275; Aubry de Reims et la scission des Normands". In: Ibidem, 68 (1984), p. 3-49. STEENBERGHEN, F. V., Maître Siger de Brabant. 1977.

29 DONDAINE, A; BATAILLON, L.-J., "Le manuscrit Vindob. Lat. 2330 et Siger de Brabant". In: Archivum Fratrum Praedicatorum, 36 (1966), p. 153-261.

30 STEENBERGHEN, F. V., Siger de Brabant d'après ses œuvres inédites, I. Les œuvres inédites v. 1 , XII, Louvain: EISP, 1931; Idem, Siger de Brabant d'après ses œuvres inédites, II. Siger dans l'histoire de l'aristotélisme. v. 2, XIII, Louvain: EISP, 1942.

${ }^{31}$ NARDI, Bruno, "Il preteso tomismo di Sigieri di Brabante." In: Giomale critico della filosofia italiana, 17 (1936), p. 26-35; Idem. "Ancora sul preteso tomismo di Sigieri di Brabante." In: Giomale critico della filosofia italiana, 18 (1937), p. 160-164. GLLSON, E., op. cit. (1940-1942).

Sobre o suposto monopsiquismo da posição averroísta, diz numa nota Nardi: "É invalso l'uso, presso molti storici della filosofia, di denominare 'monopsichismo' la teoria averroistica. Tale denominazione è fatta apposta per accrescere la confusione che è nella mente di non pochi: per Averroè, non l'anima è unica, bensi l'intelletto possibile considerato in se stesso." (NARDI, B., Sigien di Brabante nel pensiero del rinascimento italiano. Roma: Edizione Italiane, 1945, p. 33, nota 1). GRABMANN, M., Neu aufgefundene Werke des Siger von Brabant und Boetius von Dacien. Munchen: Verlag der Bayerischen Akademie der Wissenschaften, 1924.

${ }^{5}$ Sobre isto vide GILSON, E., "Boèce de Dacie et la double vérité". In: Archives d'Histoire Doctrinale et Litteraire du Moyen Age, 22, Paris: Vrin, 1956, p. 81-99; MAURER, A., "Boetius of Dacia and the Double Truth". In: Mediaeval Studies, v. XVII, Toronto, 1955, p. 233-239; LIBERA, A. de, Pensar na Idade Média, 1999, "O mito da dupla verdade", p. 116-122. 
gressos internacionais. ${ }^{36}$ Uma das conseqüências diretas da teoria monopsiquista foi a afirmação da imortalidade da alma com o conseqüente privilégio da felicidade vinculada à investigação teórica.

Convém recordar que ainda durante o Renascimento prosperou entre alguns aristotélicos esta idéia do intelecto único para todos. Com a descoberta, porém, da subjetividade, do sujeito (cogito) dotado de uma consciência e conhecedor do objeto (res extensa), o monopsiquismo deixou de ser a resposta para a questão da alma e de suas relações. A consciência, na modernidade, é entendida como relação da alma consigo mesma. Ela é intrínseca, interior ao homem, pela qual ele pode, de modo imediato e direto, desencadear o processo do conhecimento do mundo e de "conhecer-se" e "julgar-se" de modo seguro e infalível. "Cogito, ergo sum" é a forma mais acabada da auto-evidência existencial do pensamento e o "locus" privilegiado para o conhecimento do "mundo externo".

Voltando ao contexto do "averroísmo", na cultura universitária medieval estava presente um tipo de literatura "popular", diferente e mesmo contrária aos escritos dos "averroístas". O galanteio erótico, a exaltação ao adultério, as atitudes justificadas por amor, a poesia cortês, o amor cortês, expressos numa linguagem picante e obscena aos olhos da época, como o De Amore, de André Cappellan este citado por Tempier no prólogo das condenações de 1277 - e o Roman de la Rose, contribuíram para o clima "libertino" e "anárquico" que tanto preocupou os teólogos. Além disso, este tipo de literatura tinha como base de referência a natura e a ratio, embora não fossem escritos "averroístas". Certamente, a existência de problemas de comportamento, de desordem moral e doutrinal no ambiente universitário denunciados, a exemplo, por Boaventura, contribuíram para a imagem negativa das idéias dos "averroístas", embora tais atitudes juvenis fossem e ainda hoje sejam próprias da vida universitária, sem estarem ligadas necessariamente a questões doutrinais ou às idéias de Averróis. Mas, a sobrevivência do mito "dall' 'averroismo' ao 'contro natura"', segundo Bianchi, deve-se ao fato de que,

L'argomento al quale anche i "critici" più convinti sembrano puntualmente arrendersi, è che c'era comunque "necessità e urgenza" di arginare il focolaio "neopagano" della Facoltà delle Arti parigina, il cui "naturalismo" e "racionalismo" avevano "esiti nefasti" sul piano etico, sociale e religioso. Contagiata, minata dall'insegnamento "averroísta"

${ }^{36}$ Por exemplo, no caso de "averroísta", NADER, A. N., "La doctrine des deux verités chez Ibn Rochd (Averroès) et les averroistes latins". In Actos del V Congreso Internacional de Filosofia Medieval, v. II, Madrid: Nacional, 1979, p. 1048-1049. Outro exemplo recente é COSTA, José Silveira da. Averróis. O aristotelismo radical. São Paulo: Moderna, 1994. Diz este autor ao falar da doutrina da dupla verdade: "Segundo essa doutrina, defendida pelos averroistas latinos da Universidade de Paris no século XIII, a verdade filosófica não coincide necessariamente com a verdade teológica...". (p. 54). Nåo é possível identificar esta doutrina numa corrente filosófica ou mesmo em algum autor específico. É claro que, no ambiente interno da universidade, na Faculdade de Artes de Paris, o dever profissional de mestres e bacharéis em filosofia de não tratar de questões exclusivamente de fé dava margem a possíveis soluçōes do tipo "duplex", isto quando houvesse oposição entre a soluçâo filosófica e a dada pela fé. Mas a orientaçăo do estatuto de 1272 era que o filósofo não tinha o direito de decidir em favor da razäo mas, no máximo, de refutar a posição filosófica racionalmente ou de ficar em silêncio ou recusar-se a discutir a questão em causa. Sobre isto vide, DENIFLE, H., CHATELAIN, A., Chartularium Universitatis Parisiensis. Paris, 1899, I, n. 441, p. 499-500. 
con la sua prospettiva tutta terrena, di sapore rinascimentale per non dire illuministico, la gioventù studentesca si sarebbe difatti abbandonata a ogni forma di impietà, per teorizzare e praticare un "libertinismo" dalle spiccate tendenze omossessuali."

Provavelmente os excessos iniciais, tanto comportamentais como doutrinais, atribuídos ao grupo de mestres e estudantes comandado por Síger, podem ter sido resultado de posições mais extremistas defendidas por algum expoente secundário entre os simpatizantes de tais teorias e, obviamente, acabaram comprometendo o próprio líder do grupo, se é que Síger realmente desempenhou tal tarefa. ${ }^{38}$ Contudo, mesmo no campo estritamente doutrinal não é fácil dar conta da complexidade da filosofia de Síger, a qual, na opinião de Steenberghen, "est un 'aristotélisme néoplatonisant hétérodoxe ou radical', influencé à la fois par l'averroisme et par le thomisme". ${ }^{39}$ Mais especificamente, é "um aristotelismo 'peripatetizado', penetrado de neoplatonismo e de ciência árabe, e mesmo de astrologia", diz Libera. ${ }^{40}$

Este movimento filosófico ("averroísmo"), à parte as interpretações deturpadas e construções lendárias perpetuadas pela historiografia, não tinha por objetivo opor-se aos dogmas da fé; ademais os próprios textos de Averróis, numa leitura imparcial, não tinham tal escopo nem em relação à fé cristã e muito menos à fé corânica. Embora o nome de Averróis tenha servido para reunir os supostos perigos, os mais diversos roteiros dos "infiéis", talvez fosse melhor, como sugere Libera, falar de arabismo ao invés de averroismo e, assim, tentar recuperar a "herança esquecida" ou seja, o "espírito da filosofia medieval" e o "nascimento dos intelectuais" como herança dos pensadorés do Islã pelo pensamento ocidental medieval. ${ }^{41}$ Que os contemporâneos de Síger teriam identificado um movimento com idéias provenientes de Averróis, uma "corrente averroísta" perigosa à fé é "inexact et inacceptable aux yeux de l'historien", segundo Steenberghen, pela simples razão de que os filósofos-teólogos cristãos mais ortodoxos, do século XIII, reagiram pela ameaça do "aristotelismo", do "racionalismo pagão", no qual a influência de Averróis acabou por agravar a situação já em crise. ${ }^{42}$

Em relação à posição filosófica assumida por Averróis (1126-1198), muito já se discutiu, desde Alberto Magno e Tomás de Aquino, no tocante à interpretação dos textos aristotélicos e à crítica principal do Comentador a Avicena (980-1037) por não ter distinguido claramente a teologia da filosofia. As interpretações forçadas e equivocadas de Renan e seus seguidores, especialmente em relação à maneira do Comentador conceber a filosofia e 0 tipo de relação desta com a religião (tema

\footnotetext{
37 BIANCHI, L., Il vescovo e i filosofi: la condanna parigina del 1277 e l'evoluzione dell'aristotelismo scolastico. 1990 , p. $149 \mathrm{~s}$.

${ }^{3}$ S Sobre os motivos das condenaçöes, vide: STEENBERGHEN, F.V. La philosophie au XIIle siècle, 1991, p. 423; HISSETTE, R., op. cit. 1977; LAFLEUR, C. La condamnation panisienne de 1277. 1999; DONATI, Silvia. "A new witness to the radical aristotelianism condemned by Etienne Tempier in 1277". In: Miscellania Mediaevalia, 26, Berlin/New York: Walter de Gruyter, 1998, p. 371-382. STEENBERGHEN, F. V., La philosophie au XIIle siècle, 1991, p. 359.

LIBERA, A. de, Pensar na Idade Médja. 1999, p. 168.

Idem, ibid., p. 97-138.

(2) STEENBERGHEN. F, V., La philosophie au XIIle siècle. 1991, p. 357.
} 
caro a Averróis, sobretudo pelas acusações e perseguições, aparentemente religiosas, mas, no fundo, por motivação política, ${ }^{43}$ sofridas de seus contemporâneos islâmicos, e pelo modo como foi interpretado pelos latinos no confronto com a teologia cristã). Longe da falsa imagem de um pensador "excessivamente racionalista" em relação à religião ou de um "fideismo irracional" apresentado por Renan, estudos recentes demonstram o forte interesse de Averróis pelos problemas religiosos e teológicos. De modo particular uma obra, Exposição dos caminhos que conduzem à demonstração dos artigos da fé (Kašf 'an manāhiğ al-adilla), na verdade desconhecida pelos autores medievais, pois não foi traduzida para o latim, demonstra um Averróis preocupado em fornecer uma interpretação da teologia islâmica com os instrumentos sapienciais da filosofia aristotélica. ${ }^{44}$

Para interpretar corretamente as concepções doutrinais, deve-se ter claro que foi muito comum entre os historiadores sustentar, no contexto em que surgiu o "averroísmo", a imagem do século XIII dominada por duas concepções antagônicas: o agostinismo e o aristotelismo. Esta forma de entender o pensamento do século XIII é ultrapassada e equivocada, como tem sido sustentado por diversos estudiosos, a exemplo de Steenberghen. Deste modo, é importante refutar as suspeitas, os preconceitos contra os "averroístas", para poder compreender a essência desta concepção de vida filosófica, ${ }^{45}$ baseada não apenas no uso da razão, que num sentido mais lato sempre esteve presente também nas reflexões teológicas cristãs, mas no uso exclusivo da razão natural, da atividade intelectual como condição de possibilidade de dar conta criticamente e livremente das grandes questões que preocupavam o homem medievo. É necessário valorizar mais as fontes e o contexto da filosofia de Síger e de Boécio de Dácia, do que supervalorizar a exegese e o texto das condenações de 1270 e de 1277, como fizeram eminentes historiadores da filosofia medieval, a começar por Renan.

A tradução, do árabe ou diretamente do grego, do Corpus Aristotelicum foi empreitada a partir do século XII. ${ }^{46} \mathrm{~A}$ obra de Aristóteles era parcialmente conhe-

43 Cf. CRUZ HERNANDEZ, M., Abu-I-Walid Ibn Ruchd (Averroes): vida, obra, pensamiento, influencia. Córdoba: Publicaciones Del Monte de Piedad y Caja de Ahorros de Córdoba, 1986.

44 Este texto integra a trilogia Tratado decisivo sobre o acordo entre a revelação e a sabedoria (Fasl al. maqal), Destruição da 'Destruição dos filósofos' (Tahafut al-tahafut) e Exposição dos caminhos que conduzem à demonstração dos artigos da fé (Kasf 'an manahig al-adilla), publicada primeiramente por GAUTHIER, Leon, La théorie d'Ibn Rochd (1909), depois em 1942 e republicada por VrinReprise, Paris, 1983, onde Averróis trata das relações entre a filosofia e a revelação. Numa leitura atenta dessas obras percebe-se que năo há nenhuma concessão ao fideismo irracional, mas sim a busca de uma racionalizaçăn das argumentações teológicas.

45 Sobre as etapas da descoberta de Síger, particularmente, sobre os primeiros trabalhos em busca da identidade de Siger e das circunstâncias de sua morte, vide: STEENBERGHEN, F. V., Maître Siger de Brabant. 1977, p. 9-27.

4 Sobre os desdobramentos e as diferentes facetas das traducões e dos comentários das obras do Estagirita, encontramos sintetizados num excelente artigo de DE BONI, Luis A., "A entrada de Aristóteles no Ocidente Medieval. In Dissertatio, v. 1, n. 1, Pelotas, 1995, p. 65-105. Para um estudo 
cida pelos medievais antes de 1200 , embora atribuíssem ao Estagirita obras como - Liber de Causis, posteriormente identificada como pseudo-aristotélica por Tomás de Aquino, sendo individuada sua origem neoplatônica. Steenberghen rejeita a idéia de um aristotelismo latino homogêneo. Diz:

Rappelons que cet aristotélisme a toujours été en quelque mesure et sous des formes variées, un aristotélisme néoplatonisant: c'est le cas pour l'aristotélisme éclectique de la première moitié du siècle, pour l'aristotélisme de S. Bonaventure et celui d'Albert le Grand, pour le thomisme et pour l'aristotélisme hétérodoxe. ${ }^{47}$

$\mathrm{Na}$ entrada das traduções de Aristóteles, a filosofia voltou a marcar presença, com vestes, porém, que não eram mais gregas. Ela vinha do mundo cultural do Islã, com a experiência vivida num contexto cultural diverso - judeus, muçulmanos (árabes ou não árabes), cristãos do Oriente, bizantinos ou cismáticos (nestorianos, jacobitas). Foi com esta "invasão" dos escritos filosóficos árabes, dos textos de Aristóteles, misturados com textos e interpretações neoplatônicas, a leitura concordante de Aristóteles e de Platão e a experiência no confronto entre os defensores da falsafa (filosofia) e os do kalam (teologia), que os latinos se defrontaram. O interesse dos medievais era menos o Aristóteles histórico do que seu pensamento interpretado e moldado à luz dos problemas e dos debates medievais em busca da verdade. Diz Tomás de Aquino em seu comentário ao De coelo et mundus: "O estudo da Filosofia não se destina, a saber, o que outros disseram, mas a conhecer qual é a verdade das coisas". ${ }^{48}$

O interesse em fazer filosofia pelo caminho da razão natural coincidiu com a entrada das obras de Aristóteles, no Ocidente, aliado às contribuições do mundo árabe-muçulmano. O surgimento e consolidação das primeiras universidades ( $\mathrm{Pa}$ ris, Oxford, Bolonha, Pádua) não só impulsionou o desenvolvimento cultural do Ocidente latino, mas foi a condição de possibilidade de "una crescente 'professionalizzazione' del lavoro intellettuale" ${ }^{49} \mathrm{O}$ encontro do cristianismo com 0 aristotelismo no século XIII, recolocou a questão da relação entre fé e razão de maneira muito mais intensa do que nas épocas anteriores ou no modelo experimentado no mundo árabe-muçulmano, sobretudo pelo vigoroso sistema científico aristotélico construído conforme os princípios do mais puro naturalismo.$^{50}$ Esta gradual e decisiva entrada de Aristóteles no século XIII, especialmente através de disciplinas

mais detalhado, vide: GLORIEUX, P., La facultè des arts et ses maîtres au XIIle siècle. Paris: Vrin, 1971. Libera dedica várias páginas às contribuições dadas pelo Imperador Frederico II de Hohenstaufen e seu filho, Manfredo, rei da Sicilia, para o "nascimento dos intelectuais" a partir do interesse nas questões filosóficas e no financiamento das traduções enviadas para os mestres em artes de Paris - os "filósofos" como o rei os chamava e eles próprios assim se definiam - para que fossem conhecidas e ensinadas. (LIBERA, A. de, Pensar na Idade Média. 1999, p. 160-167).

47 STEENBERGHEN, F. V., La philosophie au XIIle siècle. 1991. p. 457.

48 TOMÁS DE AQUINO, De coelo et mundus, I, com. 22, Opera, ed. Fretté, t. XXIII, p. 77. "Studium philosophiae non est ad hoc quod sciatur quid homines senserint, sed qualiter se habeat veritas rerum". (Tradução de L. A. De Boni),

so STEENBERGHEN, F. V., Maitre Siger de Brabant. 1977, p. 229. 

teológico cristão. Diz Lafleur:

En effet, bien que d'abord officiellement conçue pour jouer un role essentiellement subalterne et propédeutique - la formation générale de jeunes gens supposément destinés à poursuivre leurs études dans l'une des trois facultés supérieures -, la Facultas artium parisienne s'est progressivement transformée en un véritable centre d'enseignement proprement philosophique, d'où finit clairement par émerger, à partir de 1250, une conception nouvelle du savoir humain qui, sans renier explicitement la sagesse chrétienne, parut assez la remettre en cause, du moins aux yeux des autorités ecclésiastiques, pour que l'évêque de Paris, Etienne Tempier, proclamat, en 1270 et 1277, ses célèbres condamnations. ${ }^{57}$

Como é sabido, este aristotelismo, que foi gradualmente conhecido pelos medievais, ${ }^{52}$ não foi só produto da inteligência de Aristóteles e de seus discípulos, mas contém contribuições significativas (especialmente quando o assunto adentra no âmbito metafísico transcendental do Ser Supremo, da Teologia) do neoplatonismo grego, judeu e árabe fornecidas pelos textos supostamente atribuídos a Aristóteles e pelos diversos comentários feitos às obras dele. A sabedoria cristã ancorada, sobretudo nas Escrituras, no testemunho de São Paulo, e na filosofia de Agostinho, deparou-se com um saber profano muito mais poderoso e completo quie aquele compreendido pelo tradicional esquema das artes liberais. ${ }^{53}$

Antes mesmo do conhecimento integral dos textos de Aristóteles foi muito forte a influência da filosofia árabe no pensamento latino, especialmente Avicena foi lido e estudado, desde o final do século XII, transmitindo, assim, não só muito do pensamento de Aristóteles mas, também, uma boa dose de neoplatonismo. Como sustenta Libera, "foi Avicena, não Aristóteles, que iniciou o Ocidente na filosofia" ${ }^{54} \mathrm{~A}$ forte presença da contribuição árabe, do mundo muçulmano, não

51 LAFLEUR, C.. "Scientia et ars dans les introductions à la Philosophie des maitres ès arts de l'Université de Paris au XIIIe siècle." In Miscellanea Mediaevalia, 22, 1, 1994, p. 45.

52 Em 1210 ocorreu a primeira intervenção sinodal limitada a Paris que proibia sob pena de excomunhão a leitura pública ou privada dos livros de filosofia natural (De anima, Metafisica, Fisica, De coelo, De generatione. Meteorologica, etc.) de Aristóteles e os comentários feitos ao seu texto (sem os nominar, mas provavelmente eram Avicena e Alfarabi e talvez algum texto ou idéia de Averróis). Mesmo com a repetição dessa proibição por Roberto de Courçon, em 1215, quando da aprovação dos estatutos da Universidade de Panis, na prática tais idéias de Aristóteles continuaram a ser estudadas, chegando inclusive à Faculdade de Teologia. Isto levou o Papa Gregónio IX, em 1228, a alertar os professores desta faculdade a manterem-se longe das inovaçōes provocadas pela filosofia. Consciente da ineficácia das proibiçōes, o mesmo Papa, em 1231, com a Carta "Parens scientiarum Pansius" mudou de tática, não mais impedindo a leitura dos livros proibidos, desde que fossem antes devidamente examinados e expurgados os erros neles contidos. No entanto, aconselhava aos “... magistri vero et scolares theologie in facultates quam profitentur se studeant laudabiliter exercere, nec philosophos se ostentent, sed satagant fier theodocti..." (DENIFLE, H. E CHATELAIN, A. Op. cit. p. 138, n. 79). Para maiores informaçỏes sobre as ressalvas dos teólogos ante 0 aristotelismo, vide, DE BONI, L. A. "A entrada de Aristóteles no Ocidente Medieval". In Dissertatio, 1995, p. $65-105$

53 Maria CORTI, em sua obra La felicità mentale. Nuove prospettive per Cavalcanti e Dante. Torino: Einaudi, 1983, apresenta uma interessante análise no cap. II, sobre: "Campi di tensioni" e "Campi semantici mobili" nella cultura del Duecento, p. 38-71 
evitou que diversos textos árabes importantes (como o livro de Al-Gazali, Tahafut (Refutação) que não foi traduzido e, provavelmente, os latinos não conheceram na sua totalidade. A réplica de Averróis à Tahafut, Refutação da refutação, só foi traduzida depois de 1300, pelo judeu Calonymos ben Calonymos e, portanto, nenhum dos autores do século XIII conheceu este texto, bem como outros textos (que não vem ao caso citar aqui) não foram traduzidos ou conhecidos pelos latinos, ou seja, "os latinos ignoraram parcialmente o nível das controvérsias teológicas e filosóficas atingido no mundo islâmico. ${ }^{55}$

O corpo dos escritos aristotélicos provocou tensões, discussões interpretativas de Aristóteles, de seus comentadores, das novas noções científicas greco-árabes, a ponto de dividir o próprio pensamento teológico escolástico. Antes de ensinar na Faculdade de Teologia, os futuros mestres passavam pelo ensino de filosofia na Faculdade de Artes e o contato com Aristóteles era inevitável. Daí surgem diferentes interpretações dos textos em uso, resultando em diversos tipos de "aristotelismo" ou "peripatetismo". De certo modo, "todos" conheciam as mesmas fontes, a maneira, porém, de entendê-las e interpretá-las, foi diferente, principalmente entre aqueles que não pretendiam apenas repetições dogmáticas.

O lugar do filosofar era a Faculdade de Artes, como mostra Libera, onde, a partir das obras de Aristóteles, o ideal filosófico se desenvolve entre os mestres de artes que se espelhavam no modelo dos sábios da antiguidade e, assim, consideravam o seu modo de vida de "artistas" como um estado de perfeição, isto é, no ideal de sabedoria e de felicidade intelectual. ${ }^{56}$ Os programas de estudos, as introduções à filosofia, à lógica, à física, à ética e à metafísica assumidos na Faculdade de Artes mostram a necessidade da filosofia, ainda que propedêutica à teologia. Aliás, a própria separação entre a teologia e a metafísica, na opinião de Boulnois, não é uma reivindicação dos "artistas" com seu ideal de sabedoria filosófica, de uma filosofia que parece ser um projeto impossivel, ${ }^{57}$ mas da própria teologia. ${ }^{58} \mathrm{Diz}$ ainda,

Sans nier la validité de cette interprétation, je voudrais ici attirer l'attention sur l'autre face du même phénomène. Je souhaite montrer que le rapport entre philosophie et théologie n'a pas toujours ni pour tout le monde été aussi dramatique, et mettre l'accent ici sur une tradition moins conflictuelle et une évolution moins apocalyptique: la reprise et le développement de la métaphysique, comme discipline philosophique dont la théologie a exprimé le besoin. ${ }^{59}$

65 Idem, ibid. p. 106

s6 Idem, ibid. p. 97-174.

57 STEEL, Carlos, "Medieval Philosophy: an impossibile project? Thomas Aquinas and the 'averrosistic' ideal of happiness". In Miscellanea Mediaevalia, 26, Berlin/New York: Walter de Gruyter, 1998, p. $152-174$.

se BOULNOIS, O., "Le besoin de Metaphysique" In SOLERE, J-L et KALUZA, Z. (Orgs), La servante et la consolatrice: La philosophie dans ses rapports avec la théologie au Moyen Âge. Paris: Vrin, 2002, p. $45-94$.

59 Idem, ibid. p. 50. 
Mandonnet inaugura uma divisão triádica deste período do século XIII (direita-centro-esquerda), ${ }^{\infty}$ que será ainda repetida claramente por Steenberghen. Este, num breve capitulo "Les forces en présence", de La Philosophie au XIIIe siècle, classifica as principais correntes doutrinais no cenário dos conflitos iniciados abertamente depois de 1267 , conforme o seguinte esquema: ${ }^{61}$

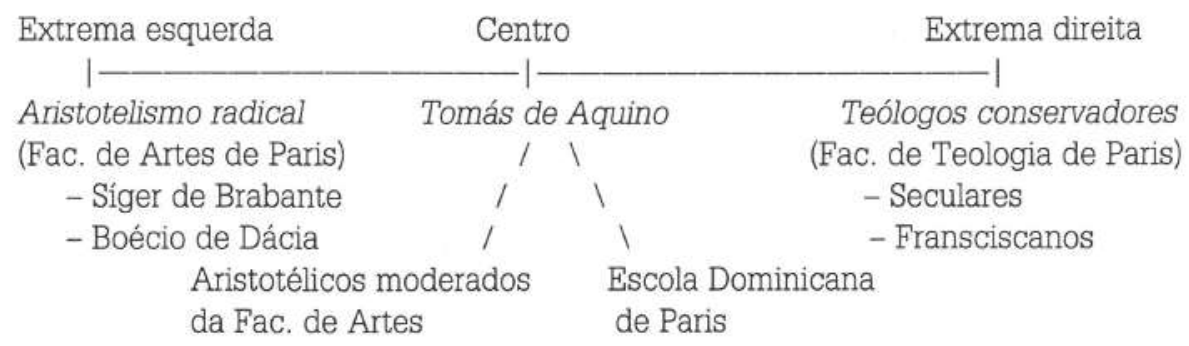

Dependendo da questão em disputa, discussão (disputatio, discussio), estes pensadores tanto podiam distanciar-se como se aproximar em seus pontos de vista, do mesmo modo, dependendo do horizonte e interesse cultural, como no caso dos mestres de artes que tinham profissionalmente a tarefa de expor (exponere), explicar (explicare) e comentar (commentare) o pensamento nos textos. Diverso é o caso dos teólogos e dos médicos. Daí a dificuldade de caracterizarem-se como corrente de pensamento, pois, em sentido estrito, somente os teólogos da Faculdade de Teologia mostravam uma posição mais unitária. Por exemplo, no discutido problema da eternidade do mundo, claramente não funciona este esquema, como bem demostrou Bianchi, que conclui: "Il vecchio dogma storiografico dell'esitenza di una 'sinistra' la cui specificità starebbe nell'acritica e servile recitazione di un verbo aristotelico accolto in ogni suo aspetto e difeso ad oltranza in una subdola professione di eterodossia, trova un'ennesima smentita."162 Sem dúvida este esquema é muito discutível, embora como esquema, acrescenta ainda Bianchi, "... trova la sua unica legittimazione in esigenze di economia mentale $e$ non può in nessun caso essere ipostatizzato". A catalogação formulista dos "ismos", em relação ao periodo escolástico, foi historicamente anacrônica e pouco

60 Cf. MANDONNET, P., op. cit. (Fribourg, 1899), p. XLII-XCII.

${ }^{61}$ STEENBERGHEN, F. V., La philosophie au XIlle siècle. 1991, p. 384s. Nas palavras do autor: "Quelles sont les forces en présence? A l'extrême gauche, au sein de la faculté des arts, le groupe inquiétant de l'anistotélisme radical, sous la conduite de Siger de Brabant et de Boèce de Dacie. A l'extrême droite, la faculté de théologie presque au complet, séculiers et franciscains, [...] appelons ce deuxième groupe le parti des théologiens conservateurs. Au centre, à mi-chemin entre les deux groupes extrêmes, se tient Thomas d'Aquin, presque seul au début, mais entouré bientôt d'un cercle de disciples où l'on peut discemer deux groupes: l'école dominicaine de Paris et les aristotéliciens modérés de la faculté des arts..."

*2 BIANCHI, L., L'errore di Aristotele... 1984, p. 166s. O autor trata da não existência de um corpo doutrinal univoco entre os intérpretes do "averroismo" (p. 35) e apresenta uma boa discussão crítica do esquema triádico nesta mesma obra, nas páginas 165-169. 
prudente numa forma de caracterização do "tipo ideal" de Max Weber, até mesmo em medievistas consagrados como Gilson que, sabiamente, reconhece:

Les appellations historiques ne sont que les symboles de faits, ou de groupes de faits, dont elles ne sauraient en aucun cas remplacer la description. [...] Aucune appellation ne désigne aucune doctrine de façon correcte, parce qu'aucune doctrine n'est exhaustivement analysable. Une doctrine ne porte correctement qu'un seul nom, celui de son auteur. ${ }^{63}$

São muitas as variáveis que são causa ou são efeitos da penetração da filosofia pagã grega no ensino da Faculdade de $\operatorname{Artes}^{64} \mathrm{e}$, de certo modo e mais em sentido negativo do que positivo para o dogmatismo cristão, também, entre os teólogos. Steenberghen destaca como consequência deste importante fato: "la conscience de plus en plus vive de l'autonomie du savoir philosophique et la naissance d'un aristotélisme hétérodoxe ${ }^{\prime \prime} .{ }^{65}$ Nos parece mais completo acrescentar: a consciência da necessidade dos teólogos, por um lado, defenderem fervorosamente a ortodoxia e, por outro lado, reforçarem suas antigas posiçōes e convicções baseadas na Escritura, nos Padres da Igreja e em Agostinho. Isto quer dizer a necessidade de entender a theologia como discurso sobre Deus, como ciência de Deus, ou mesmo, para aqueles mais moderados, revê-las, sobre novas bases, mesmo sendo neoplatônicas ou árabes, ou seja, theologia natural, usando, com mais profundidade, de uma argumentação do tipo filosófico, que resultará em uma "nova teologia". ${ }^{6}$

Contudo, a influência de Averróis nos pensadores do século XIII, longe das consagradas atribuições "irracionalistas", seja no conjunto de seu pensamento ou na relação filosofia e religião, acelerou a compreensão e a assimilação do pensamento de Aristóteles e agravou o drama intelectual cristão, especialmente pelo tipo de interpretação fornecida por ele da psicologia da inteligência, da alma, de Aristóteles. As primeiras traduções latinas de Averróis foram feitas na primeira metade do século XIII e incluem os comentários ao De Anima e à Ética a Nicôma-

${ }^{63}$ GILSON, E., "Boèce de Dacie et la double vérité". In Archives d'Histoire Doctrinale et Litteraire du Moyen Age, 1956, p. 94. Neste artigo Gilson faz uma avaliaçāo negativa do aristotelismo integral (radical). Isso continua na sua obra L'esprit de la Philosophie Médiévale e mesmo posteriormente na sua Introduction à la Philosophie Chrétienne. Diz, por exemplo, naquela importante obra: "On peut savoir ce qu'eût été l'enseignement de la philosophie dans les Universités du XIIIe siècle s'il s'était délibérément soustrait aux influences du milieu chrétien. Averroès avait tenté l'expérience avec l'Islam, les averroïstes l'ont inlassablement renouvelée en terre de chrétienté. Le résultat est celui que l'on sait: une stérilité philosophique complète [...] Si l'on regrette que le moyen âge, usant de la philosophie grecque, ne se soit pas interdit d'en abandonner la lettre [...] les averroistes sont là pour donner toute satisfaction". (L'esprit de la philosophie médiévale, 1936, vol. 2, p. 209).

${ }^{64}$ Sobre as etapas do crescimento do aristotelismo latino e os primeiros conflitos surgidos no seio da Universidade de Paris, vide: STEENBERGHEN, F. V., La philosophie au XIIle siècle. 1991, p. 72-189 e p. 357-362; LAFLEUR, C., "L' apologie de la philosophie à la Faculté des arts de Paris dans les décennies précédant les condamnations d' Etienne Tempier: la contribution didascalique des artiens". In: Miscellania Mediaevalia, 26, Berlin/New York: Walter de Gruyter, 1998, p. 383-392.

e6 Cf. BIANCHI, L.; RANDI, E., Le verità dissonanti. 1990, p. VIII-XII. 
co. Síger, porém, como os demais escolásticos, conheceu Aristóteles por outros olhos que os de Averróis.

O efervescente ambiente da Faculdade de Artes e o conhecimento cada vez mais direto dos textos do Estagirita possibilitam pensar, ao menos hipoteticamente, se o resultado, em termos gerais, alcançado pelos "averroístas latinos" teria sido o mesmo sem a influência de Averróis e dos demais pensadores árabes. No caso da particular questão sobre a felicidade intelectual, se realmente Síger e seus colegas não conheceram a obra De Animae Beatitudine, de Averróis, ou o Liber exercitationis ad viam felicitatis (Kitāb al-tanbīh 'alà sabīl al-sa 'āda), de Alfarabi (870-950), então é mérito todo destes "aristotélicos radicais" a construção teórica de uma "felicidade mental" apoiados, por um lado, na leitura da Ética a Nicômaco e, por outro, na interpretação de Averróis do De Anima de Aristótéles, em que fala do intelecto único e do conhecimento humano das substâncias separadas e de Deus pela via natural. ${ }^{68}$

67 Nesta obra Alfarabi trata do fim da vida humana que é alcançar a felicidade. Interpretando o filósofo árabe diz Rafael R. Guerrero: "La felicidad en la que piensa al-Farabi es la que se alcanza, sobre todo, en este mundo, aquella que tiene que ver con el hombre en general y no con el hombre musulmán en particular. Es una felicidad que se obtiene a través de una doble vertiente, la individual y la social: es una felicidad que sólo el hombre, en la actualización de sus potencialidades individuales, podrá alcanzar a través del cultivo de las virtudes morales e intelectuales, pero que sólo puede cumplirse dentro de una sociedad." (ALFARABI. El camino de la felicidad (Kitāb al-tanbīh "alà sabîl al-sa 'äda). Trad., introducción y notas de R. R. GUERRERO, Madrid: Trotta, 2002, p. 28.

* GEOFFROY, M. e STEEL, C., Averroès. La béatitude de l'âme. Paris: Vrin, 2001, p. 10s, sustentam a tese de que esta obra de Averróis só foi conhecida pelos latinos a partir do século XIV, embora houvesse traduçōes judias desde o século anterior. 